\title{
A rare case of biventricular non-compaction
}

\author{
Masood Pasha Syed (D) ,' Adhirath Doshi, ${ }^{2}$ Deepali Pandey (D) ,' Yugandhara Kate, \\ Robert Harizi ${ }^{2}$
}

${ }^{1}$ Department of Internal Medicine, Saint Vincent Hospital, Worcester, Massachusetts, USA ${ }^{2}$ Department of Cardiology, Saint Vincent Hospital, Worcester, Massachusetts, USA

Correspondence to Dr Deepali Pandey; drdeepalipandey05@gmail.com

This case has been presented as a poster in ACP, MA, 2018

Accepted 1 April 2020

\section{DESCRIPTION}

A 59-year-old man with a history of chronic obstructive pulmonary disease (COPD) presented with progressive dyspnoea and bilateral leg swelling over 3-4 weeks. He had dyspnoea on moderate exertion at the baseline but progressed to symptoms at rest along with new onset of orthopnoea. He reported no chest pain, palpitations, syncope, fever, chills, wheezing or productive cough. His mother and brother died at ages 54 and 44, respectively, after developing heart failure of unknown aetiology. He has a smoking history of 40 pack-year. His physical examination on admission revealed stable vitals, elevated jugular venous pulse (JVP), normal S1 and S2 sounds, regular heart rate, no murmur, rubs or gallop, diminished breath sounds in bilateral bases with occasional wheezing and bibasilar rales. His lower extremities revealed bilateral $1+$ nontender pitting oedema with clubbing.

The electrocardiogram showed sinus tachycardia with a right axis deviation with evidence of left ventricular hypertrophy and right atrial enlargement. There were no ischaemic changes. Chest X-ray (CXR) was normal. An echocardiogram showed global hypokinesia with a left ventricular ejection fraction of $35 \%-40 \%$ with grade I diastolic dysfunction and probable noncompaction of the left ventricle (figures 1 and 2 ). Right ventricular function and right ventricular systolic pressure were normal. A provisional diagnosis of left ventricular non-compaction (LVNC) was made. He was started on furosemide, lisinopril and carvedilol. Bilateral cardiac catheterisation showed normal coronary arteries with elevated pulmonary wedge pressure consistent with non-ischaemic cardiomyopathy. Cardiac MRI confirmed increased trabeculation

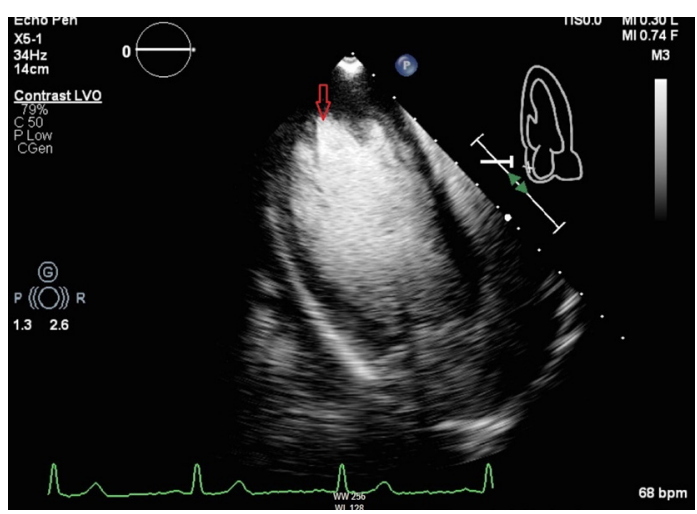

Figure 1 An echocardiogram with contrast shows intertrabecular crevices filled with contrast (red arrow).

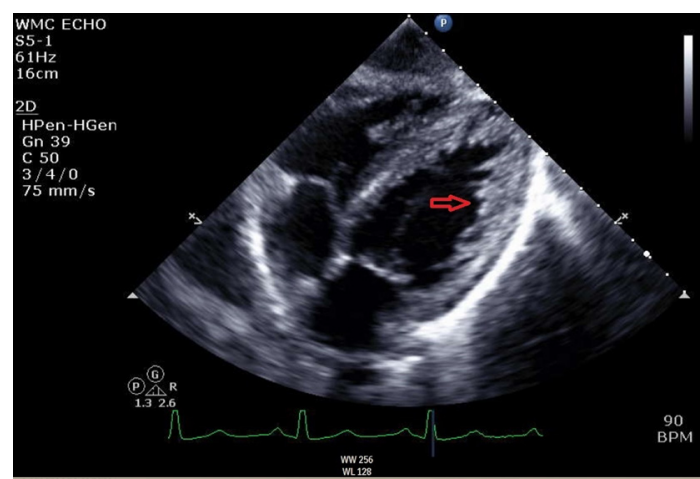

Figure 2 An echocardiogram shows left ventricular non-compaction (red arrow).

in both ventricular apices with impaired biventricular systolic function confirming biventricular non-compaction (BVNC) cardiomyopathy (figures 3-5).

Non-compaction is thought to be due to intrauterine arrest of compaction of the loose interwoven meshwork present in fetal myocardial primordium. ${ }^{12}$ Alternatively, the pronounced hypertrabeculation may be due to altered regulation in cell proliferation, differentiation and maturation during ventricular wall formation. ${ }^{12}$ Clinically, it may have variable manifestations of heart failure, chest pain, thromboembolic events, atrial and ventricular arrhythmias and risk of sudden cardiac arrest. $^{12}$ It is recommended to undergo Holter monitoring to screen for arrhythmias as there is a role of an implantable cardioverter-defibrillator (ICD). ${ }^{1}$ Oral anticoagulation is recommended if there is arrhythmia, atrial or ventricular thrombi or for primary prevention of thrombus in case of left ventricular (LV) dysfunction. ${ }^{1}$ Our patient presented

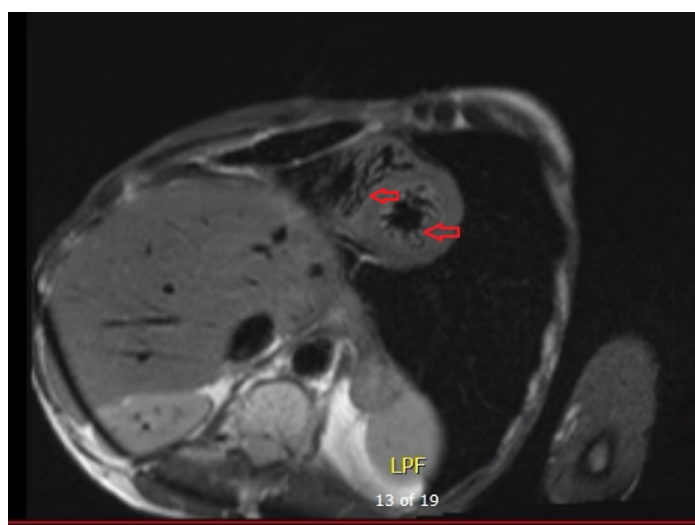

Figure 3 A cardiac MRI shows bi-ventricular noncompaction (red arrows). LPF: low pass filter. 


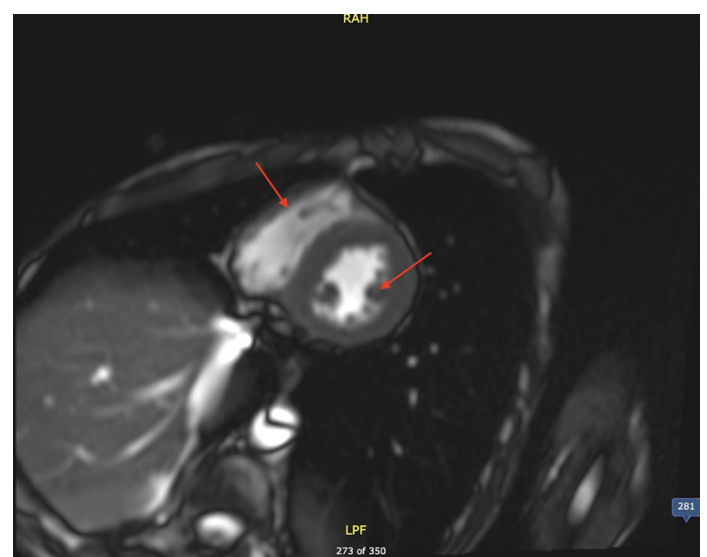

Figure 4 A cardiac MRI with contrast—end-diastolic view showing biventricular non-compaction (red arrows). LPF: low pass filter.

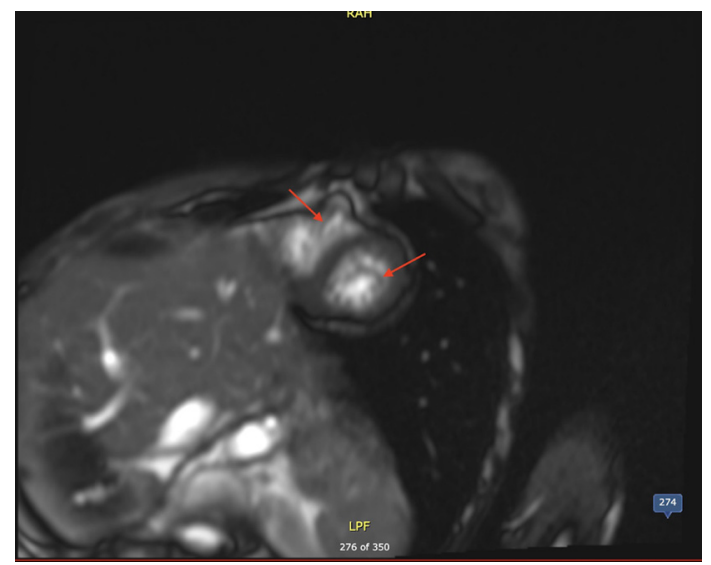

Figure 5 A cardiac MRI with contrast-end-systolic view showing biventricular non-compaction (red arrows). LPF: low pass filter.

with new-onset heart failure with biventricular systolic dysfunction, and non-obstructive coronary artery disease (CAD) on cardiac catheterisation suggesting BVNC to be aetiology of heart failure. There have been very few cases of patients with BVNC reported, presenting as heart failure, tonic-clonic seizure. ${ }^{3-5}$ Holter monitor did not reveal any arrhythmias and he did not meet criteria for ICD placement or anticoagulation. A recent follow-up cardiac MRI showed persistent BVNC but normalisation of LV systolic dysfunction with optimal guideline-directed medical therapy for cardiomyopathy. Genetic counselling was advised as it can be familial. He chose not to be evaluated as he improved symptomatically with medical therapy and continues to be in the follow-up. In our patient, we can speculate that the family history of heart failure of unknown aetiology was likely due to non-compaction cardiomyopathy.

Contributors MPS: writing, editing and critical review of the manuscript. AD: retrieval of images and critical review of the manuscript. DP: critical review and editing of the manuscript. YK: retrieval of images and editing of manuscript. RH: inception of the idea and critical review of the manuscript.

Funding The authors have not declared a specific grant for this research from any funding agency in the public, commercial or not-for-profit sectors.

Competing interests None declared.

Patient consent for publication Obtained.

\section{Learning points}

- Isolated ventricular non-compaction can be sporadic or familial and is characterised by prominent trabeculae and deep intertrabecular recesses. Left ventricular noncompaction (LVNC) has been found in $0.014 \%-1.3 \%$ of patients undergoing echocardiography (biventricular noncompaction being even rarer), and it is an uncommon cause of heart failure and sudden cardiac death.

- Echocardiography is used both to establish the diagnosis of non-compaction cardiomyopathy and as an aid during follow-up. Jenni et al proposed the following three criteria for diagnosis ${ }^{6}:(1)$ a thickened left ventricular wall composed of two layers: a thin compacted epicardial layer and a noncompacted endocardial layer with numerous prominent trabeculations and deep recesses: a maximum ratio of noncompacted to compacted myocardium being $>2: 1$ at end systole in the parasternal short-axis view, (2) colour Doppler evidence of flow within the deep intertrabecular recesses and (3) prominent trabecular meshwork in the left ventricular (LV) apex or midventricular segments of the inferior and lateral wall.

- Cardiac MRI (CMR) criteria for LVNC are still evolving. The following end-diastolic and end-systolic CMR criteria have been proposed as per various studies conducted so far. (1) A maximum end-diastolic non-compacted to compacted myocardial thickness ratio of $>2.3$ was the best criterion for LVNC and yielded a sensitivity of $86 \%$ and specificity of $99 \%$ for LVNC. (2) A trabeculated LV mass $>20 \%$ of global LV mass was identified as a criterion for LVNC with a sensitivity of $94 \%$ and a specificity of $94 \%$. (3) Fractal dimension as a quantitative measure of trabeculation is high in LVNC and may be very accurate; however, further follow-up is needed to better identify its role. (4) An end-systolic non-compacted to compacted (thickness) ratio $\geq 2.0$ was found to be more strongly associated with heart failure and with adverse events (heart failure, death, heart failure readmission, embolic events and ventricular arrhythmias) than other criteria for LVNC.

Provenance and peer review Not commissioned; externally peer reviewed.

\section{ORCID iDs}

Masood Pasha Syed http://orcid.org/0000-0002-3252-9094

Deepali Pandey http://orcid.org/0000-0003-2292-4004

\section{REFERENCES}

1 Arbustini E, Weidemann F, Hall JL. Left ventricular noncompaction: a distinct cardiomyopathy or a trait shared by different cardiac diseases? J Am Coll Cardiol 2014;64:1840-50.

2 Shemisa K, Li J, Tam M, et al. Left ventricular noncompaction cardiomyopathy. Cardiovasc Diagn Ther 2013;3:170-5.

3 Tatu-Chitoiu A, Bradisteanu S. A rare case of biventricular non-compaction associated with ventricular septal defect and descendent aortic stenosis in a young man. Eur J Echocardiogr 2008;9:306-8.

4 Rao G, Tauras J. Biventricular noncompaction cardiomyopathy in an adult with unique facial Dysmorphisms: case report and brief review. Case Rep Cardiol 2015;2015:831341

5 Wang J, Kong X, Han P, et al. Combination of mitochondrial myopathy and biventricular hypertrabeculation/noncompaction. Neuromuscul Disord 2016;26:165-9.

6 Jenni R, Oechslin E, Schneider J, et al. Echocardiographic and pathoanatomical characteristics of isolated left ventricular non-compaction: a step towards classification as a distinct cardiomyopathy. Heart 2001;86:666-71. 
Copyright 2020 BMJ Publishing Group. All rights reserved. For permission to reuse any of this content visit https://www.bmj.com/company/products-services/rights-and-licensing/permissions/

BMJ Case Report Fellows may re-use this article for personal use and teaching without any further permission.

Become a Fellow of BMJ Case Reports today and you can:

- Submit as many cases as you like

- Enjoy fast sympathetic peer review and rapid publication of accepted articles

Access all the published articles

Re-use any of the published material for personal use and teaching without further permission

Customer Service

If you have any further queries about your subscription, please contact our customer services team on +44 (0) 2071111105 or via email at support@bmj.com.

Visit casereports.bmj.com for more articles like this and to become a Fellow 